\title{
ВЛИЯНИЕ ИНСТИТУЦИОНАЛЬНОЙ СТРУКТУРЫ НА ОБЩЕСТВЕННОЕ ПРОИЗВОДСТВО
}

\author{
(C) 2018 Марчук Алина Александровна" \\ аспирант, департамент экономической теории \\ Финансовый университет при Правительстве Российской Федерации \\ 125468, г. Москва, Ленинградский пр-т, д. 49 \\ E-mail: alina.marchuk@minfin.ru
}

Статья посвящена развитию теории X и Ү-институциональных матриц. В статье, в частности, обосновывается, что влияние институциональной структуры с доминированием X-матрицы осуществляется не через поддержку коллективных хозяйств и естественных макро- и территориальных монополий, а через поддержку отраслей, производящих продукты коллективного потребления.

Ключевые слова: институциональная структура, общественное производство, коммунальные отрасли, коммунальные продукты, коммунальное производство.

Главным объектом изучения институциональной экономики, очевидно, является влияние институтов на хозяйственную жизнь или даже на все общественное производство. Конечно же, такое исследование предполагает выявление характеристик институтов, с которыми связывается это влияние, представляющее собой не что иное, как выяснение соответствующей структуры институтов, или институциональной структуры. Как пишут В.В.Вольчик и А.А. Оганесян в статье «Институты, информация и институциональная структура экономики» (2010), «институциональная структура - это определенный упорядоченный набор институтов, создающих матрицы экономического поведения, определяющих ограничения для хозяйствующих субъектов, которые формируются в рамках той или иной системы координации хозяйственной деятельности» [1, с. 30]. В X-Y-теории, или теории $\mathrm{X}$-Ү-матриц, главным теоретиком которой является С.Г. Кирдина, в институтах страны, с целью изучения их влияния на общественное производство, выделяются «базовые» институты, отражающие сущность совокупности институтов страны и «институциональные формы», представляющие собой проявления этой сущности, т.е. реальные, осязаемые институты. При этом и те, и другие, делятся на институты экономики, политики и идеологии. Как пишет С.Г. Кирдина в работе «Институциональная структура современной России: эволюционная модернизация» (2004), «базовые институты (- это институты.А.М.), образующие глубинные основания соци- альных взаимодействий по поводу совместного проживания в рамках единого социума, что требует связи и согласований между ними в трех важнейших сферах, составляющих модель общества, которой мы и будем оперировать: экономики, политики и идеологии» [2].

Базовые институты экономики, политики и идеологии образуют институциональную матрицу, или «невидимый» скелет общества, его «архетипическая структуру». Оригинальность теории С.Г. Кирдиной состоит в том, что, согласно этой теории, институциональная матрица любой страны состоит из Х-матрицы и Ү-матрицы при доминировании одной из них (или ее базовых институтов). Каждая матрица состоит из одинакового количества базовых экономических, политических и идеологических институтов. Каждому базовому Х-институту соответствует базовый Ү-институт, имея в виду то, что оба института имеют одинаковое функциональное назначение. Фактически пары X и Ү-институтов представляют типы базовых институтов, выделяемые по одному признаку, характеризующиеся при этом противоположными свойствами.

В составе экономических базовых институтов выделяются (в скобках указан признак выделения): 1) редистрибуция (распределение) и обмен (купля продажа) (движение благ). 2) верховная условная собственность и частная собственность (закрепление благ), 3) кооперация и конкуренция (взаимодействие агентов), 4) служебный труд и наемный труд (организация тру-

\footnotetext{
* Научный руководитель Лебедев К.Н., д.э.н. доцент, профессор Департамента экономической теории Финуниверситета.
} 
да, 5) ограничение издержек (X-эффективность) и максимизация прибыли (Y-эффективность) (сигнал обратной связи, или эффективности) [3, c. 431].

В составе политических базовых институтов выделяются (в скобках указан признак выделения): 1) административно-территориальное деление и федеративно-территориальное устройство (федерация), 2) иерархическая вертикаль власти во главе с центром и самоуправление и субсидиарность (устройство системы управления) 3) назначение и выборы (замещение управленческих позиций), 4) общее собрание и единогласие и многопартийность и демократическое большинство (порядок формирования решений), 5) обращения по инстанциям и судебные иски (механизм обращения по инстанциям) [3, с. 432].

В составе идеологических базовых институтов выделяются (в скобках указан признак выделения): 1) коллективизм и индивидуализм (детерминанта социального действия), 2) эгалитаризм и стратификация (нормативное представление о социальной структуре, 3) порядок и свобода (доминирующие социальные ценности), 4) ориентированная на благополучие трудовая мотивация и денежно-ориентированная трудовая мотивация (трудовая мотивация), 5) интегрализм, генерализация и дискретность, специализация (привычные стереотипы мышления) [3, c. 434].

При этом доминирующая матрица (ее базовые институты) определяет пределы действия дополнительной (комплементарной) матрицы (ее институтов). И, что еще очень важно в X и Y-теории, дополнительная (комплементарная) матрица (ее базовые институты), при оптимальном соотношении между базовыми X и Ү-институтами, способствует стабильному социально-экономическому развитию страны, например, когда (при доминировании Ү-матрицы) частный сектор экономики дополняется государственным.

В X и Y-теории рассматривается взаимовлияние общественного производства и институциональной структуры страны. Прежде всего, рассматриваются причины доминирования в стране X и Y-матрицы. По мнению С.Г. Кирдиной, это доминирование определяется доминированием в общественном производстве страны коммунальной или некоммунальной материально-технологической среды (МТС), под которой понимается общественная инфраструктура и отрасли, важные для жизнеобеспечения населения институтами. Коммунальная МТС состоит из отраслевых систем, для которых характерна технологическая неразрывность, т.е. систем, части которых не могут быть обособлены без их развала, как, например, система железнодорожных путей, нефте- и газопроводные системы, централизованные городские системы теплоснабжения и др. в нашей стране. Фактически коммунальная МТС представляет собой совокупность макроэкономических и территориальных естественных монополий. В свою очередь, некоммунальная МТС состоит из отраслевых систем, части которых функционируют обособленно, что способствует эффективному функционированию данных систем. Доминирование коммунальной МТС среды обусловливает доминирование в стране X-матрицы с ее базовыми институтами, так как обеспечение функционирования этой МТС требует объединения людей под единым хозяйственным руководством, в связи с чем в стране формируются административно-территориальные структуры и коммунитарные ценности, закрепляющие в сознании народа соответствующее экономическое и политическое устройство страны. Доминирование некоммунальной МТС обусловливает доминирование в стране Ү-матрицы с ее базовыми институтами, так как обеспечение ее функционирования требует обособления товаропроизводителей и их соединения посредством рынка, в связи с чем в стране формируются федеративные политические структуры и индивидуалистические субсидиарные ценности, закрепляющие подобное экономическое и политическое устройство страны в сознании ее народа. Понятно, что соответствие МТС и матриц объясняется наиболее эффективным способом управления МТС.

В свою очередь, доминирование коммунальной или некоммунальной МТС определяется климато-географическими условиями государства. В стране с рисковыми природными условиями для земледелия и другой деятельности (суровый климат, угрозы наводнений, землетрясений и т.д.), а также однородной и однообразной территорией или, наоборот, крайне неоднородной и разнообразной, формируется преимущественно коммунальная МТС и, следовательно, доминирует Х-матица, а в стране с малорисковыми природными условиями для деятельности и средними разнородностью и разнообразием территории формируется преи- 
мущественно некоммунальная МТС и, следовательно, доминирует Ү-матрица. Исходя из соответствующих климато-географических условий страны, по мнению С.Г. Кирдиной, в нашей стране и азиатских и латиноамериканских странах доминирует X-матрица, а в основной массе стран Европы и США - Ү-матрицы [2]. Конкретно доминирование в нашей стране X-матрицы объясняется С.Г. Кирдиной суровыми условиями ведения сельского хозяйства и осуществления лесных и речных промыслов [3, с. 270-272] и наличием обширной системы речных путей [3, c. 272].

Что касается институциональных форм, т.е. реальных, или осязаемых и ощущаемых, институтов, то они, по мнению С.Г. Кирдиной, охватывают все правила (и механизмы, обеспечивающие их выполнение), регламентирующие отношения между людьми, в том числе контракты и внутриорганизационные правила, о чем можно судить по приводимым примерам институциональных форм: контракты, механизм планирования, порядок установления цен, процедура выборов [3, с. 244].

На наш взгляд, слабостью X и Y-теории является неопределенность составных частей понятия «материально-технологическая среда». Не уточняется, какие отрасли входят в социальную инфраструктуру и являются важными для обеспечения жизнедеятельности всего населения страны. Представляется, что вместо этого понятия следует использовать понятие «общественное производство», характеризуя его преимущественно как коммунальное или некоммунальное. Соответственно, преобладание коммунального общественного производства обусловливает доминирование X-матрицы, а некоммунального Y-матрицы.

Другой слабостью является положение о том, что доминирование той или иной матрицы требует доминирования той или МТС. На наш взгляд, исходя из тезиса Х и Y-теории о «вечном» доминировании в стране той или иной матрицы [2], необходимо исходить из того, что доминирование той или иной МТС для обеспечения доминирования в стране той или иной матрицы, должно было иметь место лишь в период становления государства, т.е. на последующих этапах развития страны доминирование X-матрицы может сопровождаться доминированием коммунальной МТС, или коммунального общественного производства, а Ү-матрицы - доми- нированием некоммунальной МТС, или некоммунального общественного производства.

На наш взгляд, следует отказаться и от тезиса о «вечном» доминировании в стране $\mathrm{X}$ или Y-матрицы и одновременном доминировании их базовых институтов. Обоснованием является сказанное К. Марксом в предисловии работы «К критике политической экономии» (1859) об эпохе социальной революции, возникающей вследствие развития общественного производства. К. Маркс характеризует ее как «переворот во всей громадной надстройке» [4, с. 7]. Надстройка же - юридические, политические, религиозные, художественные, философские, идеологические формы, в которых социальная революция осознается [4, с. 7]. Фактически, согласно марксистской теории, надстройка - то же самое, что институциональная структура, в том числе институциональная матрица, страны, если к способу производства отнести все четыре сферы общественного производства - производство, распределение, обмен, потребление - к чему в итоге пришла советская политическая экономия [5, c. 306]. Очевидно, что переворот в институциональной структуре, в том числе в институциональной матрице, и есть смена доминирования одной матрицы другой (или их базовых институтов). Логично предположить, что этот переворот есть реакция институциональной матрицы на изменение в доминировании коммунального или некоммунального общественного производства.

С положением X-Y-теории о том, что доминирование в стране X-матрицы было обусловлено соответствующими климато-географическими условиями страны, можно согласиться. Однако объяснение данной теорией механизма влияния институциональной структуры на развитие общественного производства в нашей стране характеризуется существенными недостатками. Вообще, влияние институциональной структуры на общественное производство состоит в следующем: если конструируемые или заимствуемые из-за рубежа институциональные формы соответствуют институциональной матрице страны (доминированию X-матрицы при оптимальном соотношении между X и Ү-базовыми институтами), то институциональная структура способствует развитию общественного производства, если эти формы ей не соответствуют, то тогда развития общественного производства институциональной структурой сдерживается. 
При этом влияние этого несоответствия, согласно X-Y-теории, осуществляется через создание или, наоборот, разрушение коллективных хозяйств в сельском, лесном и рыбном хозяйстве и естественных макроэкономических и территориальных монополий, что ускоряет или, соответственно, замедляет развитие страны. Однако, как выясняется, на основе этого механизма реально нельзя объяснить многие явления в социально-экономической динамике страны, в частности индустриализацию 1861-1913 гг. и советскую индустриализацию 1928-1941 гг., как это пытается делать С.Г. Кирдина [3, с. 285]. Дело в том, что отрасли промышленности не являются естественными монополиями, и в ходе индустриализации в отдельных отраслях создавалось и функционировало по нескольку или даже множеству предприятий. Так, в ходе советской индустриализации было построено и вступило в строй только три специализированных тракторных гиганта: Сталинградский тракторный завод (Т3) в 1930 г., Харьковский ТЗ в 1931 г. и Челябинский Т3 в 1933 г. [6]. Таким образом, требуется поиск иного механизма влияния институциональной структуры на развитие общественного производства.

По нашему мнению, коммунальная институциональная структура (структура с доминированием X-матрицы) поддерживает создание и функционирование не коллективных хозяйств и монополий, а предприятий, выпускающих коммунальные продукты (продукцию и услуги), к которым относятся продукты коллективного потребления (использования), например, автобусы или электроэнергия, или продукты, сообщающие полезный эффект одновременно нескольким лицам, например, офисный или торговый центр, занимаемый одновременно несколькими предприятиями.

Использование коммунальных продуктов как раз и характеризуется отношениями между пользователями, представленными в российской институциональной матрице, т.е. состоящими в доминировании Х-базовых институтов экономики, политики и идеологии, например при использовании торгового центра. Так, превалируют Х-базовые институты экономики: распределение площадей предшествует заключению договоров аренды, преобладает «верховная» собственность владельца центра над собственностью арендаторов, во взаимоотношениях между арендаторами преобладает коо- перация и др. Х-базовые институты политики: сдаваемые помещения дифференцируются по этажам, т.е. имеется территориальное устройство, управление офисным хозяйством централизовано, назначение освободившихся офисных помещений преобладает над их выбором и др., Х-базовых институтов идеологии: в использовании офисного центра превалируют коллективизм, эгалитаризм, порядок и др. Таким образом, для российской институциональной структуры, при условии соответствия институциональных форм институциональной матрице, характерна поддержка развития отраслей, выпускающих коммунальные продукты, или коммунальных отраслей.

Важно отметить, что при традиционной и авторской трактовке отраслей, поддерживаемых российской институциональной структурой, значительная масса поддерживаемых производств совпадает. Так, при авторской трактовке коммунальных отраслей поддержку также получают единые электроэнергетическая сеть, производство электроэнергии, железнодорожная сеть России, нефте- и газопроводы, но в данном случае потому, что соответствующими сетями одновременно пользуется множество лиц, а электроэнергия одновременно поступает всем ее получателям. С другой стороны, при этой трактовке коммунальных производств не рассматривается как поддерживаемое российской институциональной структурой сельское, лесное и рыбное хозяйство, так как продукция данных отраслей является продукцией индивидуального потребления.

Авторская трактовка коммунальных отраслей, или отраслей, поддерживаемых российской институциональной структуры, позволяет объяснить многие неудачи и успехи российского общественного производства. Она позволяет объяснить, в частности, тотальную неудачу с развитием в стране сельского хозяйства, производства легковых автомобилей, одежды и обуви, компьютеров, смартфонов, бытовой электротехники (холодильников, телевизоров, посудомоечных машин, бытовых кондиционеров и т.д.) - вся эта продукция является продукцией индивидуального потребления. Она позволяет объяснить слаборазвитость российского финансового рынка [7, с. 7-8] и обосновать формирование в стране нефинансовой экономики [8] - финансовые услуги являются услугами индивидуального потребления, и их производ- 
ство не поддерживается институциональной структурой страны. С другой стороны, авторская трактовка коммунальных отраслей позволяет объяснить былые успехи российского производ- ства широкофюзеляжных пассажирских самолетов, современные успехи ракетно-космической отрасли, производства военных самолетов, ракетно-артиллерийского вооружения.

\section{Библиографический список}

1. Вольчик B.B., Оганесян A. A. Институты, информация и институциональная структура экономики //JOURNAL OF ECONOMIC REGULATION (Вопросы регулирования экономики). - 2010. - Том 1._ № 2.- C. 30-42.

2. Кирдина С.Г. Институциональная структура современной России: эволюционная модернизация // Вопросы экономики, 2004. № 10. С. 89-98 [Электронный ресурс] URL: https://www.researchgate.net/ publication/48376697_Institucionalnaa_struktura_sovremennoj_Rossii_evolucionnaa_modernizacia (дата обращения: 15.12.2018).

3. Кирдина С.Г. Институциональные матрицы и развитие России: введение в Х-Ү-теорию. Санкт Петербург.2014. 468 с.

4. Маркс, К. К критике политической экономии / Маркс К., Энгельс Ф. Сочинения. Том 13. Изд. 2-е.- М.: ГОСУДАРСТВЕННОЕ ИЗДАТЕЛЬСТВО ПОЛИТИЧЕСКОЙ ЛИТЕРАТУРЫ, 1959.771 [XXVI] с. С. 1-167.

5. Будович Ю.И. Дискуссия о предмете экономической теории в ХІХ в.: перевод в конструктивное русло. Москва. 2015.536 с.

6. Индустриализация CCCP: тракторные заводы. Американский след // LIVEJOURNAL. Катаклизмы и повседневность. Журнал «Русский техник» и тракторные заводы в CCCP. 16.02.2016 [Электронный pecypc] URL: https://harmfulgrumpy.livejournal.com/358126.html (дата обращения: 23.12.2018).

7. Лебедев К.Н. «Ключевая» роль финансов в социально-экономическом развитии» // Экономические науки. 2018. № 163. С. 7-15.

8. Лебедев К.Н. Экономика без финансов // Вопросы экономики и права. 2018. № 120. С. 45-53. 